\title{
Recuperando la memoria del centenario de la Independencia de México: la restauración de un recurso fotográfico
}

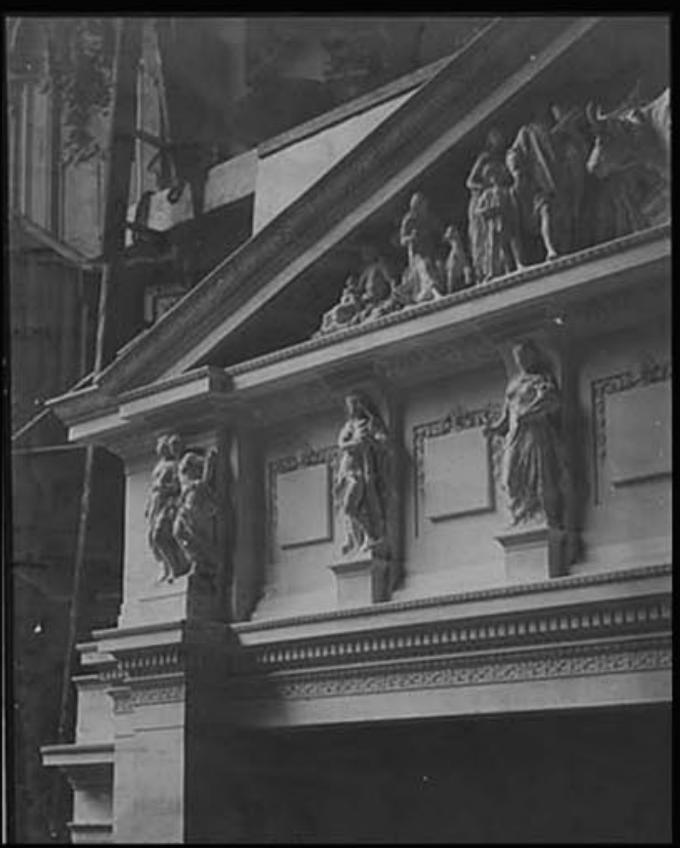

\author{
Ma. Estíbaliz Guzmán Solano \\ Diana Lorena Díaz Cañas
}

\section{Introducción}

n el mes de enero de 2009, docentes y estudiantes de la Especialidad en Conservación y Restauración de Fotografías (ECRF) de la Escuela Nacional de Conservación, Restauración y Museografía del Instituto Nacional de Antropología e Historia (ENCRYM-INAH), México, iniciaron la restauración de una admirable colección fotográfica que da cuenta tanto de los concursos organizados para los festejos del centenario de la Independencia de México que tuvieron lugar en 1910 como de los proyectos arquitectónicos presentados. Dicha colección, que es parte de los acervos del archivo del Centro Nacional de Investigación, Documentación e Información de Artes Plásticas del Instituto Nacional de Bellas Artes (Cenidiap-INBA), está compuesta por 32 impresiones de plata-gelatina y colodiones sobre papel de fibra.

Inicialmente, las fotografías pertenecieron a dos dependencias: la Secretaría de Comunicaciones y Obras Públicas, y la Dirección de las Obras del Palacio Legislativo Federal; sin embargo, a lo largo de 100 años pasaron por diversas instituciones, para finalmente ser trasladadas a las bodegas del Cenidiap, donde se almacenaron en fundas de cartón. Hace cuatro años la colección fue dada a conocer a especialistas en restauración de la ECRF, quienes a simple vista detectaron el gran potencial documental en las imágenes representadas, así como varios deterioros: suciedad, acreciones de lodo, abrasiones, rayones, manchas de pintura, escurrimientos, deformaciones, cartones delaminados, roturas $y$, en algunas piezas, hongos.

Las investigaciones histórica y material realizadas por estudiantes y profesores de la ECRF a lo largo de tres ciclos académicos (2008-2011) han proporcionado información que, por una parte, permite entender la relevancia de esta colección para nuestra sociedad y, por la otra, ha servido de fundamento en las discusiones teóricas de algunas intervenciones, en las que la estabilización de las fotografías ha implicado afectaciones en las características de la colección como una unidad.

Por tanto, en el presente REPORTE se detallan algunos procesos realizados para la recuperación de una colección que estaba olvidada y que, se espera, podrá estudiarse desde otros puntos de vista e incluso exhibirse en un futuro. 


\section{La colección fotográfica}

Siguiendo pistas encontradas en firmas, sellos, inscripciones, recortes de periódico y, por supuesto, las imágenes fotografiadas, se realizó la investigación histórica pertinente. La información recopilada condujo rápidamente a la memoria fotográfica alusiva a los festejos del primer centenario de la Independencia que tuvieron lugar en 1910, durante la gestión presidencial de Porfirio Díaz, quien con diferentes fines políticos promovió la inauguración de varias obras monumentales y conmemorativas en la ciudad de México, como parte de estas celebraciones (García 1911: VII).

Las obras de renombradas edificaciones, como el Palacio Legislativo - cuya construcción, según inscripciones en algunas fotografías, inició en 1901-y el Monumento a la Independencia, estuvieron a cargo de algunos de los arquitectos más importantes de la época, ${ }^{1}$ quienes, como complemento al diseño de sus proyectos arquitectónicos y diseños escultóricos, elaboraron maquetas, planos y prototipos de esculturas que, a su vez, documentaron mediante imágenes elaboradas con las técnicas fotográficas en auge a finales del siglo XIX y principios del siglo XX (Figuras 1 y 2), hoy desaparecidas. Además de conformar la colección fotográfica que nos ocupa, estas imágenes se reprodujeron con el fin de registrar y difundir los logros alcanzados durante el Porfiriato en publicaciones de época.

Las fotografías que nos ocupan registran, asimismo, varios proyectos arquitectónicos que participaron en los concursos para la edificación de monumentos que habrían de inaugurarse en las fiestas del centenario, tales como el Panteón Nacional, la Fuente Monumental del Paseo de la Reforma, además de diversas expresiones escultóricas como los pegasos que engalanarían el Teatro Nacional, inmuebles destinados al adorno de la ciudad de México (Figura 3).

Mientras que algunos de estos proyectos de monumentos se concluyeron para entrar en servicio, e incluso hoy, 100 años después de su construcción, cumplen funciones activas como referentes de la capital mexicana, otros sólo se llevaron a cabo parcialmente debido al estallido de la Revolución mexicana en 1910, por lo que las porciones construidas eventualmente se adecuaron a edificios existentes. Otros ejemplos más, como la Fuente Monumental del Paseo de la Reforma, nunca se ejecutaron.

Los integrantes de la ECRF llevaron a cabo en forma paralela las indagaciones histórica y estética, y el análisis material de cada fotografía. ${ }^{2}$ Como resultado, se iden-

\footnotetext{
${ }^{1}$ El arquitecto Antonio Rivas Mercado fue autor del proyecto del monumento hoy conocido como El Ángel de la Independencia (García 1911), mientras que el arquitecto Émile Bénard diseñó el monumento del Palacio Legislativo, ambos ubicados en la ciudad de México (Pérez 2009). ${ }^{2}$ Las licenciadas Ma. Estíbaliz Guzmán y Diana Díaz, y el químico Javier Vázquez, profesores de la ECRF (ENCRYM-INAH) y doce alumnos
}

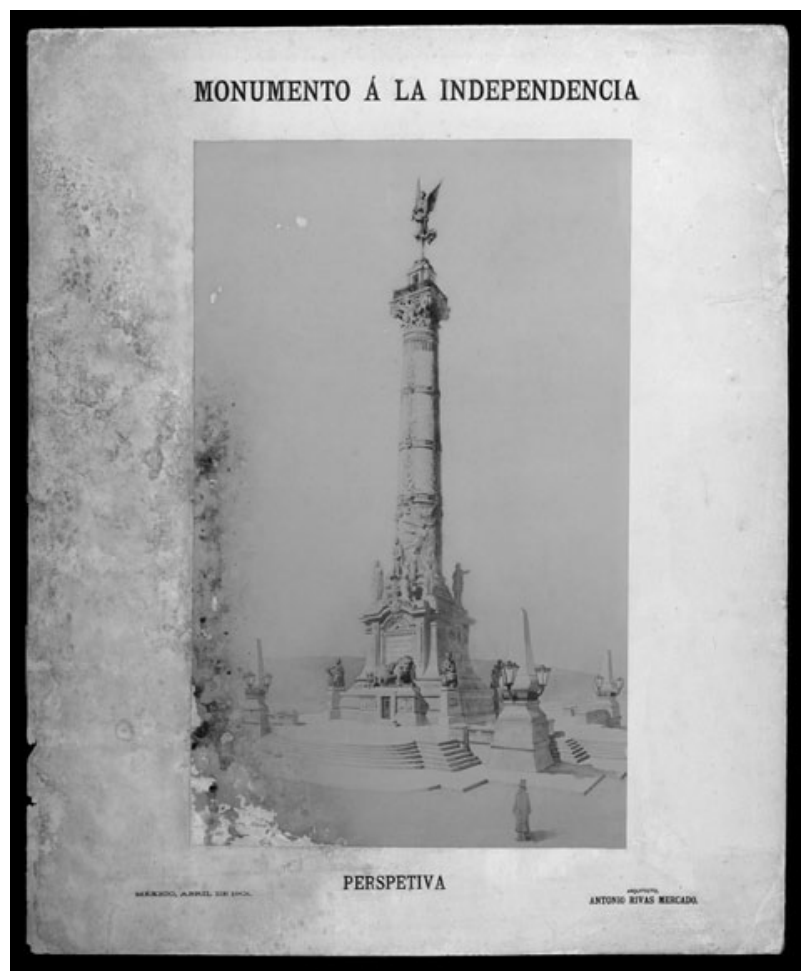

FIGURA 1. Imagen fotográfica del proyecto del Monumento a la Independencia. Perspectiva núm. 34-09 (Fotografía cortesía: ECRF, ENCRYM-INAH, 2009).

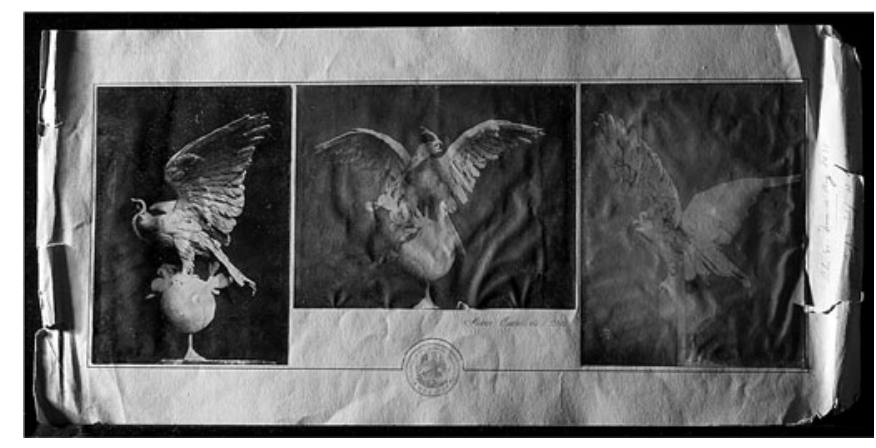

FIGURA 2. Fotografía de maqueta del águila, cuyo destino original era el Palacio Legislativo y actualmente adorna el Monumento a la Raza (Fotografía cortesía: ECRF, ENCRYM-INAH, 2010).

tificaron materiales constitutivos relevantes, tales como plata (sustancia formadora de la imagen), bario y estroncio (estrato intermedio de sulfato de bario), oro (virador), azufre (fijador), aluminio y cromo (endurecedores), entre otros. Asimismo, se reconoció la presencia de tintas grasas en sellos, impresos e inscripciones hechas a mano. Adicionalmente, los análisis a la gota hicieron posible la identificación de aglutinantes de gelatina y colodión, materiales que definen dos técnicas fotográficas distintas.

(generaciones 2008-2011) realizaron análisis con fluorescencia de rayOS X (FRX), radiación ultravioleta y observación macro/microscópica con diferentes tipos de luces, técnicas con las que identificaron tanto materiales constitutivos como diferentes técnicas fotográficas empleadas. 


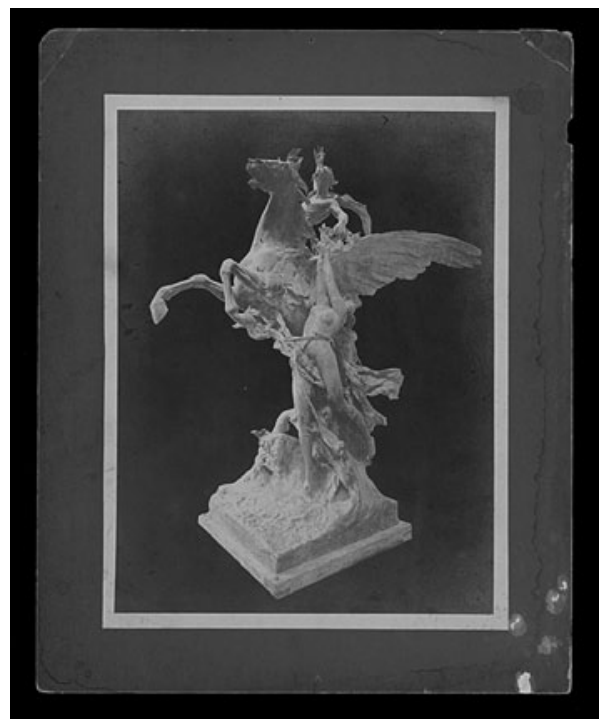

FIGURA 3. Fotografía de la maqueta de uno de los pegasos que actualmente se encuentran en el Palacio de Bellas Artes-INBA, antiguo Teatro Nacional (Fotografía cortesía: ECRF, ENCRYM-INAH, 2010).

Las impresiones con aglutinante de gelatina presentaban diferencias tonales (cálidas y neutras), y fue a partir de su comparación detallada como se distinguieron las fotografías obtenidas por contacto directo (printing out paper, POP) de las impresiones de plata-gelatina de revelado (developing out paper, DOP). Cabe señalar que las impresiones tanto de colodión como de gelatina eran técnicas fotográficas que se empleaban comúnmente a finales del siglo XIX y principios del siglo XX (Lavedrine 2009), cuyo procesamiento responde de forma específica al manejo de diferentes materiales que eran accesibles en el mercado de la época.

\section{Estado de conservación e intervenciones realizadas}

Las 32 fotografías de la colección poseían un soporte secundario en cartón o cartulinas, montaje que, en la mayoría de los casos, representaba un riesgo para las impresiones, ya por el tipo de adhesión de éstas a los cartones o cartulinas, ya por el estado quebradizo y friable de los soportes secundarios. Adicionalmente, amén de los diferentes grados de alteración, las obras tenían un común denominador: un grueso estrato de suciedad y manchas por escurrimientos.

Con base en esta evaluación del estado de conservación, los integrantes del ECRF establecieron necesidades y tratamientos específicos para cada técnica fotográfica, que incluyeron desde limpiezas superficiales y estabilización de soportes originales, hasta desmontajes, laminados y reemplazos de ciertos montajes.

En algunos casos las limpiezas minuciosas y detalladas fueron suficientes para recuperar acabados, texturas, tonos y detalles, entre otras cualidades artísticas que se ha-

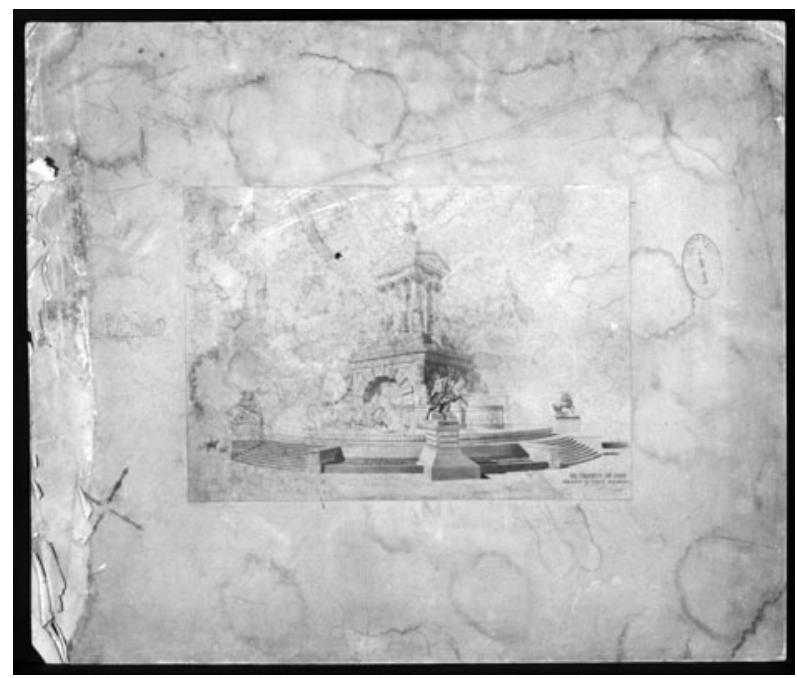

FIGURA 4. Imagen fotográfica de la Fuente Monumental del Paseo de la Reforma. Antes de tratamiento (Fotografía cortesía: ECRF, ENCRYM-INAH, 2009).

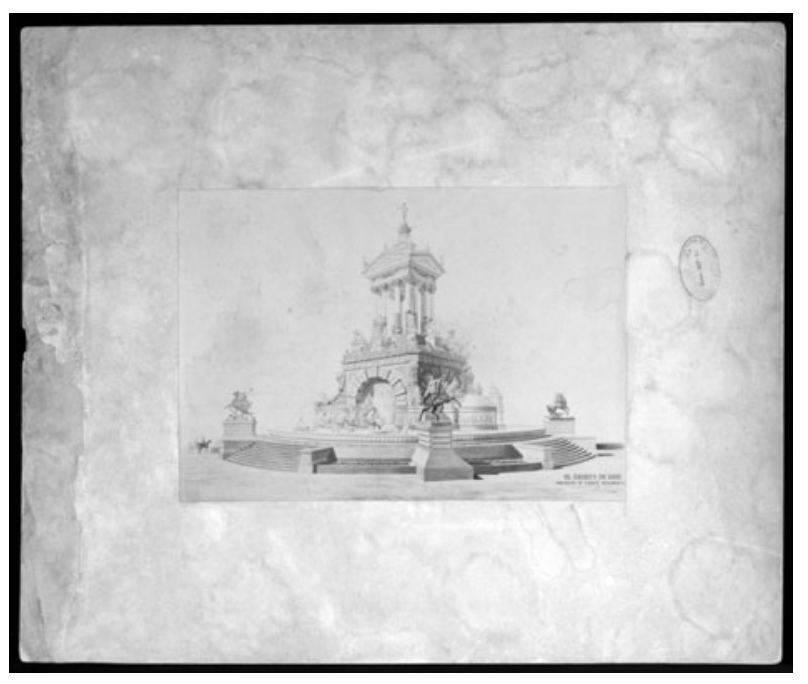

FIGURA 5. Imagen de la fuente monumental al finalizar de tratamiento. Limpieza superficial con métodos en seco y acuosos, y uso de geles con secuestrantes y sustancias que permitieron disminuir los frentes de secado. Consolidación del soporte secundario de cartón, el cual estaba delaminado. El empleo de la mesa de succión permitió recuperar el plano y consolidar los cartones de forma simultánea (Fotografía cortesía: ECRF, ENCRyM-INAH, 2009).

bían visto aminoradas por una significativa capa de suciedad superficial, manchas de foxing, ${ }^{3}$ escurrimientos y rayones con grafito. Aunada a la limpieza, la consolidación de los soportes secundarios que estaban delaminados recuperó la resistencia mecánica de los mismos. Los resultados obtenidos fueron satisfactorios, tal y como lo muestra el registro previo y posterior a la intervención (Figuras 4 y 5 ).

${ }^{3}$ El término foxing se refiere a manchas pequeñas y redondas, de color rojo o café amarillento, encontradas en soportes de papel, cuyas tres principales causas de origen han sido descritas por Soyeon (2007: 137-152). 
Es de notar que dos fotografías sobre el Palacio Legislativo que se elaboraron con el mismo proceso fotográfico: plata-gelatina en papel de fibra DOP, presentaron en sus soportes secundarios niveles de acidez y resistencia física disímiles, situación que llevó a una discusión teórica sobre el nivel de intervención necesario para conservar la unidad en ambas imágenes en una estrategia a largo plazo.

Con base en ello se determinó que para la primera fotografía tan sólo se realizaría una limpieza cuidadosa de las superficies y una reducción de manchas del soporte secundario, tratamientos que serían suficientes para recuperar las características formales de la imagen y llevar la atención del espectador hacia los infinitos detalles de la maqueta representada (Figura 6).

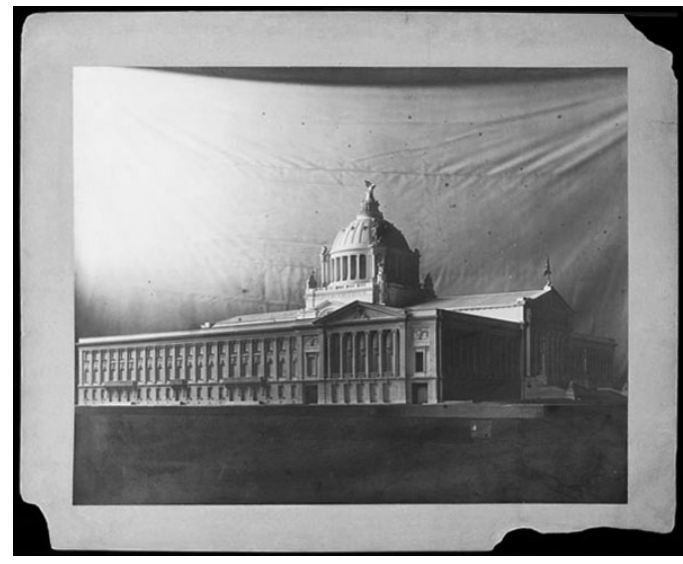

FIGURA 6. Imagen fotográfica de la maqueta del Palacio Legislativo al finalizar el tratamiento (Fotografía cortesía: ECRF, ENCRYM-INAH, 2010).

El soporte secundario de la segunda fotografía se encontraba, además, muy debilitado, ya que presentaba una rotura que comprometía su estabilidad; por ello se decidió que este soporte, que afortunadamente no presentaba inscripciones ni sellos, se reemplazara por un material nuevo. Este segundo tratamiento involucró el desmontaje de la fotografía, la consolidación del aglutinante de gelatina, la corrección de plano del conjunto, el laminado de la impresión fotográfica y el montaje perimetral en un nuevo soporte de cartón. El resultado visual de la intervención en esta fotografía no difirió de su análoga (Figuras 7 y 8 ).

Otras fotografías de menor formato, que mostraban imágenes de maquetas de frisos con alegorías, presentaban severos pliegues y dobleces que ponían en riesgo al aglutinante de gelatina y a la imagen de plata. Algunas coloraciones rosadas y negras, así como la descamación del aglutinante de gelatina, reflejaban la presencia de microorganismos: hongos y bacterias, por lo que fue necesario llevar a cabo un minucioso trabajo de limpieza y desmontaje de fotografías conservando el soporte secundario, así como procesos de desinfección, corrección de

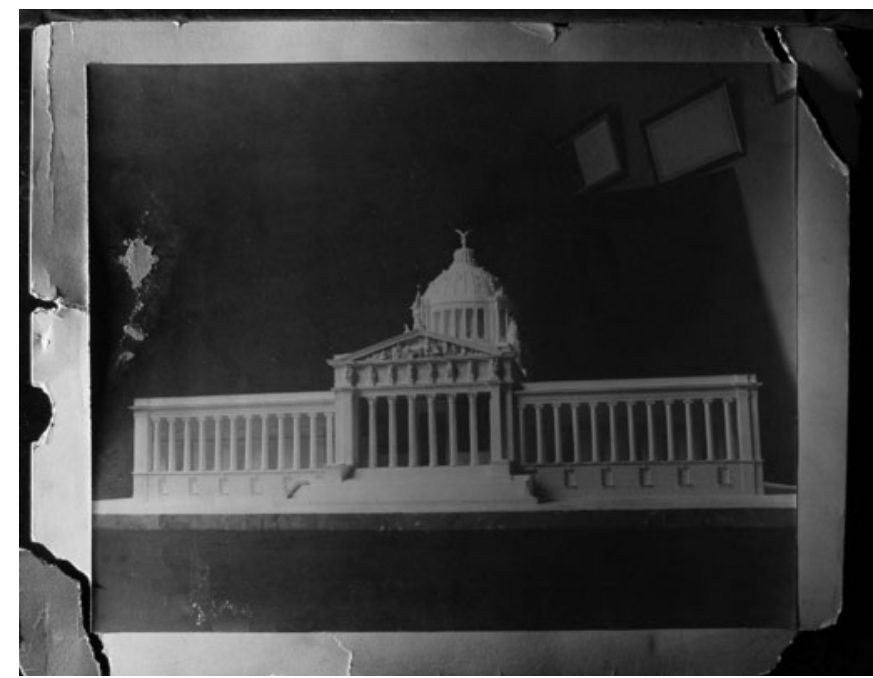

FIGURA 7. Fotografía de la maqueta del Palacio Legislativo: adhesión total al soporte secundario de cartón, el cual presentaba una rotura al centro, así como una baja resistencia y flexibilidad (Fotografía cortesía: ECRF, ENCRYM-INAH, 2010).
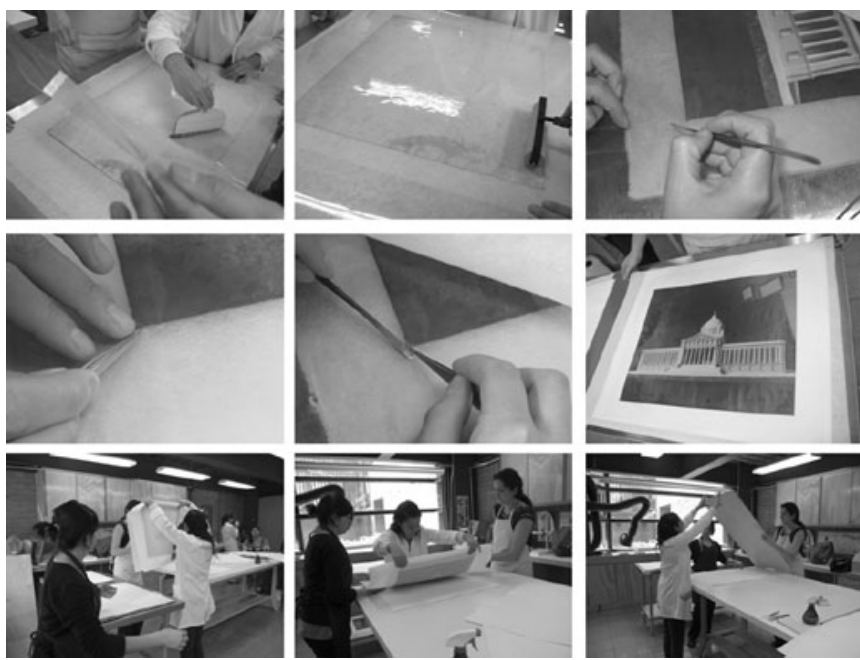

FIGURA 8. Laminado realizado a una de las dos fotografías que representan la maqueta del Palacio Legislativo (Fotografía cortesía: ECRF, ENCRYM-INAH, 2011).

plano de ambos soportes, consolidación, unión de rasgaduras, laminados y montaje en los soportes originales.

En estos casos, las reflexiones giraron en torno de la manera más adecuada de fijar nuevamente las fotografías al soporte secundario sin sobrepasar el criterio de mínima intervención necesaria, ya que originalmente estaban adheridas a éste por el perímetro del reverso. Desafortunadamente, el montaje original favoreció la formación de arrugas en la fotografía por movimientos diferenciales considerables entre ambos soportes, debidos a fluctuaciones de humedad en sus resguardos.

Así, después de realizar probetas y someterlas a escenarios ficticios, con cambios fuertes y constantes de humedad relativa en fotografías laminadas y adheridas a un soporte de cartón similar, se determinó que lo más apro- 
piado para evitar la formación de este tipo de arrugas era adherir por completo las fotografías a su soporte secundario, empleando materiales reversibles y realizando técnicas de montaje que implicaran la menor cantidad de humectación posible. Este montaje fue un proceso minucioso, ya que se cuidó que las fotografías volvieran a coincidir dentro del margen original marcado en el soporte secundario (Figuras 9 y 10).

En otro ámbito de la colección, vale señalar que 10 impresiones de gran formato $(48 \times 38.6 \mathrm{~cm}$, aproximadamente), elaboradas a base de aglutinante de colodión POP semimate sobre papel de fibra, que retratan los elementos escultóricos pertenecientes al Panteón de Dolores (Figura 11), muestran detalles $-v$. gr. líneas que corresponden a roturas en los negativos - que permiten inferir que provienen de negativos de vidrio. Estos colodiones se encontraban montados en soportes secundarios de cartón delgado color crema, con un papel azulado como acabado en el anverso e inscripciones en tinta que señalan los precios y las dimensiones de las esculturas, junto con recortes de periódico que explican las escenas escultóricas.

En este conjunto de impresiones de colodión aparecían varios deterioros que hacían indispensable una serie de intervenciones mayores. Los desprendimientos significativos del soporte primario de las fotografías, las notorias deformaciones de éstas y de sus respectivos soportes secundarios - que incluían un crecimiento local de éstos, lo que no permitía una devolución de plano local ni la readhesión de los estratos-, así como un fuerte deterioro físico-químico por acción de hongos pennicillum en más de $50 \%$ del soporte secundario, guiaron la intervención hacia el reemplazo del cartón. ${ }^{4}$

${ }^{4}$ La maestra Gabriela Cruz y la bióloga Irais Velasco (Laboratorio de Biología, ENCRyM-INAH) realizaron la toma de muestras e identificación de microorganismos.

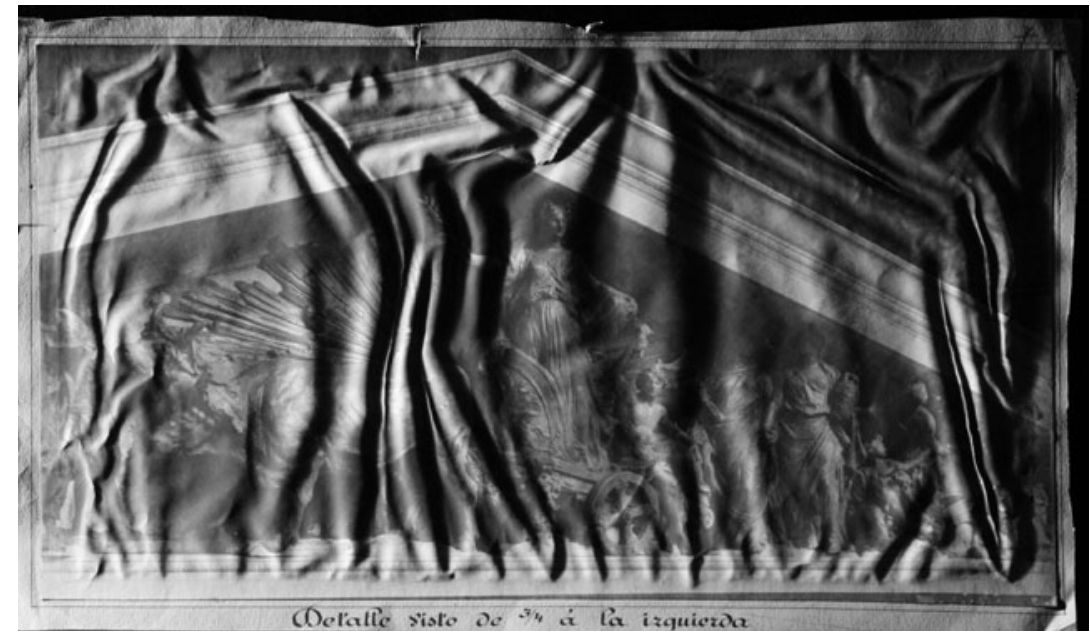

FIGURA 9. Imagen fotográfica de la maqueta del friso del Palacio Legislativo, antes de su restauración (Fotografía cortesía: ECRF, ENCRYM-INAH, 2010).

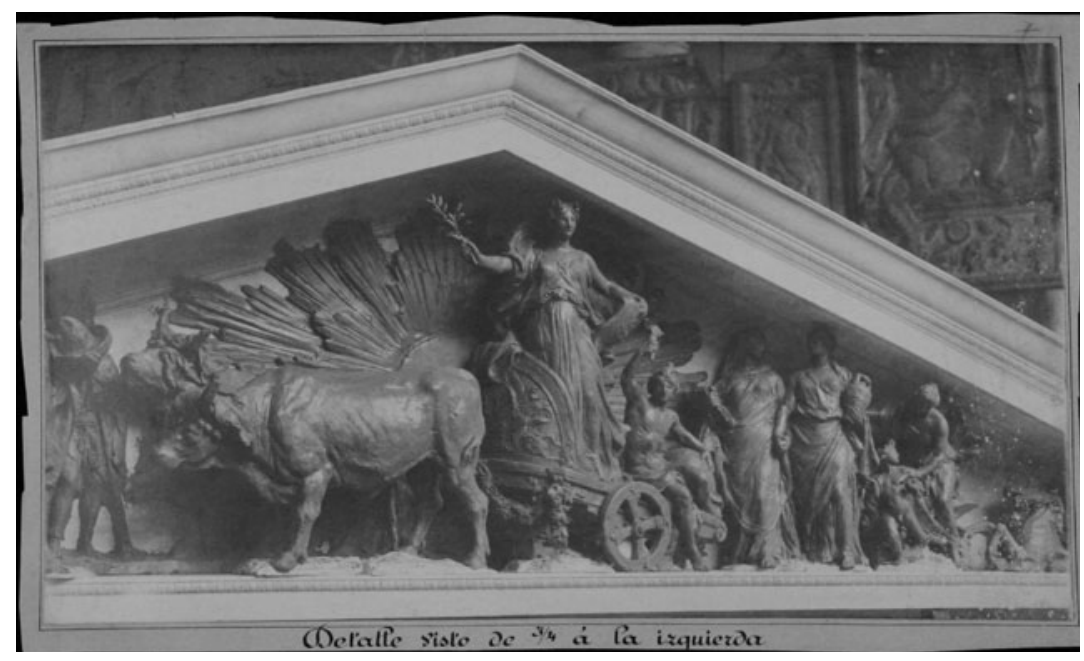

FIGURA 10. Imagen fotográfica de maqueta del friso del Palacio Legislativo, después de su restauración (Fotografía cortesía: ECRF, ENCRYM-INAH, 2010).

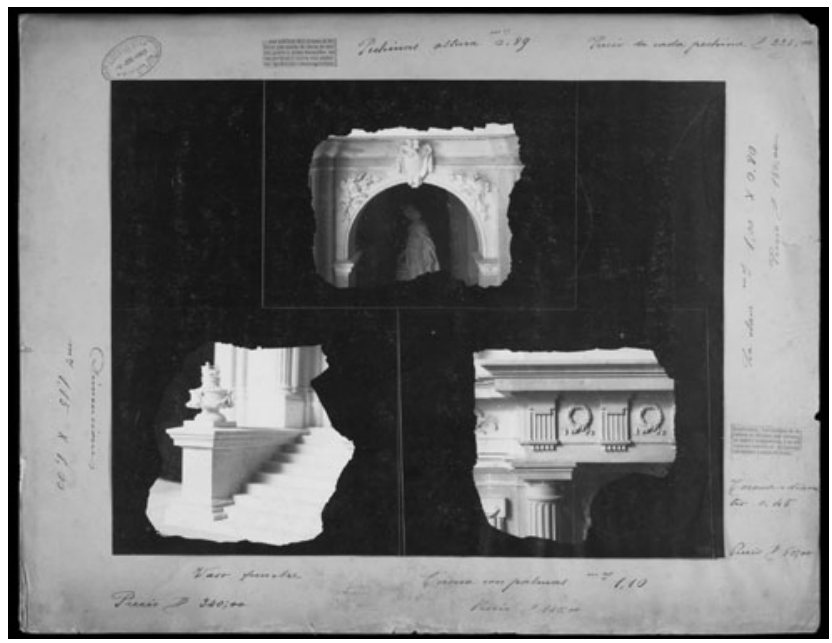

FIGURA 11. Fotografía de detalles de elementos decorativos que conforman parte del Panteón de Dolores (Fotografía cortesía: ECRF, ENCRYM-INAH, 2010). 
Durante este tratamiento fue necesario desprender los tres estratos constitutivos: fotografía, papel azulado y cartón deteriorado, y, tras desechar el soporte de cartón, los dos primeros se lavaron, desinfectaron, laminaron y volvieron a montar en una cartulina libre de ácido, cuyo grosor es similar al del original, mediante la técnica del dacron lining. Este montaje consistió en adherir, primero, una tela dacrón a una base (tabla, mesa o malla), y, subsecuentemente, el cartón secundario, el papel azul, y finalmente la fotografía y recortes de impresos, previamente humedecidos. El sistema de montaje, que implicó gran cantidad de agua,

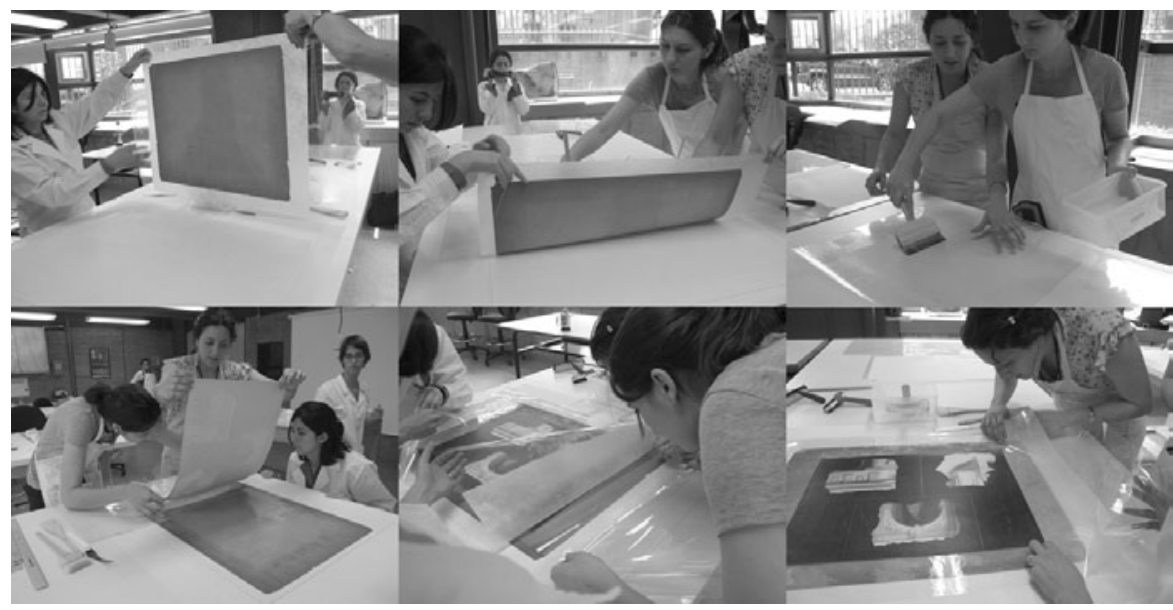

FIGURA 12. Detalles del dacron lining realizados en la fotografía titulada "Vaso funerario" (Fotografía cortesía: ECRF, ENCRYM-INAH, 2011). se secó paulatinamente quedando totalmente adherido a la tela dacrón y a la base y, por consiguiente, sin riesgo de deformaciones por el secado diferencial de los múltiples estratos. Gracias a estas intervenciones se recuperó no sólo la estabilidad material de las fotografías para su adecuada lectura y consulta, sino la belleza de un proceso fotográfico que desapareció en las primeras décadas del siglo Xx (Figura 12).

\section{Conclusiones}

Con el ejercicio especializado de varios profesores y doce estudiantes, se han recuperado diferentes aspectos documentales y estéticos de esta colección. Las fotografías se estabilizaron por medio de tratamientos que aunque puedan considerarse polémicos —en tanto que implicaron la remoción de algunos soportes originales o el empleo de procesos acuosos-, estuvieron encaminados a la recuperación de los diferentes valores históricos y tecnológicos de la colección.

Las investigaciones históricas y los análisis de materiales constitutivos, junto con el reconocimiento de las cualidades artísticas y documentales de la colección, enriquecieron las discusiones teóricas entre alumnos y profesores en torno de las acciones necesarias para estabilizarla y realzar los aspectos afectados en cada una de las fotografías.

Los tratamientos realizados permitieron, además de innovar en varios aspectos las técnicas de restauración de fotografías utilizadas en México, como la humectación por ultrasonido, la consolidación en mesa de succión, la desinfección y el dacron lining modificado, iniciar investigaciones en la ECRF sobre el uso de mezclas de adhesivos naturales y semisintéticos; acerca del empleo de adhesivos a base de ésteres de celulosa reactivados; métodos y materiales para desinfección; la caracterización de impresiones de colodión, así como el seguimiento de los factores que determinan la efectividad de los diferentes métodos de humectación, laminado y secado en las fotografías.

Hasta el momento se han intervenido 26 de 32 fotografías, cuya restauración está documentada en los respectivos informes de las generaciones 2008-2009, 2009-2010 y 2010-2011, que pueden consultarse en la biblioteca de la ENCRYM-INAH. En 2012 se concluirá la restauración de la colección, que regresará al CenidiapINBA y, con fortuna, quizá se dé a conocer a los mexicanos en una próxima exposición museográfica.

\section{Referencias}

\section{García, Genaro}

1911 Crónica oficial de las fiestas del primer centenario de la Independencia de México, México, Museo Nacional.

Lavédrine, Bertrand 2009 Photographs of the Past: Process and Preservation, Los Ángeles, Getty Conservation Institute.

Pérez Síller, Javier y Martha Bénard Calva 2009 El sueño inconcluso de Émile Bénard y su Palacio Legislativo, hoy Monumento a la Revolución, México, Artes de México.

Soyeon, Choi

2007 "Foxing on paper: A literature review", Journal of the American Institute for Conservation, 2 (46): 137-152. 


\section{Resumen}

En enero de 2009 el taller de restauración de la Especialidad de Conservación y Restauración de Fotografías (ERCF) de la Escuela Nacional de Conservación, Restauración y Museografía del Instituto Nacional de Antropología e Historia (ENCRYM-INAH) dio inicio a la recuperación de una colección de 32 fotografías de principios del siglo XX, que actualmente pertenecen al Cenidiap-INBA. Se trata de imágenes producto de diversos procesos fotográficos y en variados soportes que muestran una serie de proyectos arquitectónicos y escultóricos, en dibujo y maqueta, elaborados para su construcción rumbo a las celebraciones del centenario de la Independencia de México en 1910. A lo largo de 100 años esas fotografías estuvieron bajo la custodia de diferentes instituciones y presentaban diversos grados de deterioro. Este REPORTE detalla el proceso de restauración de 26 de las obras, mediante el cual se recuperaron características documentales y estéticas de la colección, y se implementaron tratamientos innovadores para la restauración de fotografías en México.

\section{Palabras clave}

Centenario, Independencia, México, fotografía, restauración

\section{Abstract}

In January 2009, the Conservation Workshop from the diploma course in Restoration and Conservation of Photographs at the Escuela Nacional de Conservación, Restauración y Museografía (ENCRYM) and the Instituto Nacional de Antropología e Historia (INAH) began the restoration of a collection of 32 photographs from the early $20^{\text {th }}$ Century that currently belongs to Cenidiap-INBA. The images show architectural and sculptural projects planned for the centennial celebrations of Mexico's independence in 1910. For over 100 years these photographs were in the custody of different institutions and presented different degrees of deterioration. This article details the restoration process of 26 of the photographs, in which documentary and aesthetic characteristics of the collection were restored and innovative treatments in restoring photographs in Mexico were implemented.

\section{Keywords}

Centenary, Independence, Mexico, photography, restoration

Título en inglés: Reviving the Memory of the Centenary of Mexican Indepen-

dence: the Restoration of Photographs 